Canadian

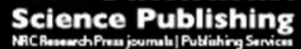

Canadian Journal of Physiology and Pharmacology Revue canadienne de physiologie et pharmacologie

\title{
Microarray analysis of pancreatic gene expression during biotin repletion in biotin-deficient rats
}

\begin{tabular}{|r|l|}
\hline Journal: & Canadian Journal of Physiology and Pharmacology \\
\hline Manuscript ID: & cjpp-2014-0517.R2 \\
\hline Manuscript Type: & Article \\
\hline Complete List of Authors: & $\begin{array}{l}\text { Dakshinamurti, Krishnamurti; Dept. Biochemistry and Medical Genetics, } \\
\text { Bagchi, Rushita; University of Manitoba, Physiology \& Pathophysiology } \\
\text { Abrenica, Bernard; St. Boniface Research Centre, } \\
\text { Czubryt, Michael; University of Manitoba, Physiology \& Pathophysiology }\end{array}$ \\
\hline Keyword: & biotin, pancreas, microarray, deficiency, repletion \\
\hline
\end{tabular}




\title{
Microarray analysis of pancreatic gene expression during biotin repletion in biotin-deficient rats
}

\author{
Krishnamurti Dakshinamurti, Rushita A. Bagchi, Bernard Abrenica, Michael P. Czubryt*
}

Institute of Cardiovascular Sciences, St. Boniface Hospital Research Centre, Faculty of Health

Sciences, University of Manitoba

*Address for correspondence:

R4008 St. Boniface Hospital Research Centre

351 Tache Avenue

Winnipeg, Manitoba, Canada

R2H 2 A6

Tel. 204-235-3719

Fax 204-231-1151

Email mczubryt@sbrc.ca

Keywords: biotin, pancreas, microarray, deficiency, repletion 


\section{ABSTRACT}

Biotin is a B vitamin involved in multiple metabolic pathways. In humans, biotin deficiency is relatively rare but can cause dermatitis, alopecia and perosis. Low biotin levels occur in type II diabetes, and biotin supplementation with chromium may improve blood sugar control. The acute effect on pancreatic gene expression of biotin repletion following chronic deficiency is unclear, therefore we induced biotin deficiency in adult male rats via a $20 \%$ raw egg white diet for 6 weeks. Animals were then randomized: one group received a single biotin supplement and returned to normal chow lacking egg white, while the second group remained on the depletion diet. After one week, pancreata were removed from biotin-deficient (BD) and biotin-repleted (BR) animals and RNA isolated for microarray analysis. Biotin depletion altered gene expression indicative of inflammation, fibrosis and defective pancreatic function. Conversely, biotin repletion activated numerous repair and anti-inflammatory pathways reduced fibrotic gene expression and induced multiple genes involved in pancreatic endocrine and exocrine function. A subset of results was confirmed by qPCR analysis, as well as by biotin treatment of pancreatic AR42J cells. The results indicate that biotin repletion, even after lengthy deficiency, results in the rapid induction of repair processes in the pancreas.

Keywords: biotin, pancreas, microarray, deficiency, repletion 


\section{INTRODUCTION}

The role of biotin as the prosthetic group of the four biotin-dependent carboxylases in higher organisms is well recognized. In view of the roles of these carboxylases in metabolism, the requirement of biotin for cell viability, growth and differentiation was established. However, biotin also appears to have a role in cell function other than as the prosthetic group of biotin enzymes. It influences processes such as proliferation of the mesenchyme and spermatogenesis (Dakshinamurti 2005, 2006). A direct effect of biotin at the transcriptional level has been shown for key enzymes of glucose metabolism such as glucokinase, a key glycolytic enzyme (Chauhan and Dakshinamurti 1991; Romero-Navarro et al. 1999) and phosphoenolpyruvate carboxykinase, a key gluconeogenic enzyme (Dakshinamurti and Li 1994). The effects of biotin depletion and repletion in three distantly-related eukaryotes, i.e. yeast (Saccharomyces cerevisiae), nematode (Caenorhabditis elegans) and rat (Rattus norvegicus), point to a strongly selected role of biotin in the control of carbon metabolism (Ortega-Cuellar et al. 2010).

In studies using pancreatic islets, the effect of in vivo biotin supplementation in the diet on rodent pancreatic islets was studied (Lazo de la Vega-Monroy et al. 2013). Biotin supplementation augmented the proportion of beta cells by enlarging islet size and increasing the mRNA expression of adhesion proteins participating in the maintenance of islet architecture. Thus, in vivo biotin supplementation augmented beta cell proportion as well as its function. Conversely, it has been reported that the circulating biotin level is lower in type 2 diabetic patients compared to normoglycemic individuals (Maebashi et al. 1993). Supplementation of biotin plus chromium has also been shown to improve glucose metabolism and glycemic control in clinical trials involving type 2 diabetic patients (Albarracin et al. 2008; Singer and Geohas 2006), and furthermore improves atherogenic risk factors and serum lipids in both diabetic and 
non-diabetic individuals (Albarracin et al. 2007; Geohas et al. 2007; Revilla-Monsalve et al. 2006). Biotin thus appears to be a critical determinant of normal pancreatic function.

Using a well-established rat model, we demonstrate here that biotin repletion following chronic depletion results in myriad changes in pancreatic gene expression. These changes include induction of anti-inflammatory pathways, increases in endocrine and exocrine function, and reduced fibrosis marker expression. These results suggest that restoration of biotin to deficient individuals may improve pancreatic gene expression, even after a long period of deficiency, and that these reparative processes are induced relatively quickly. Similarly, treatment of AR42J pancreatic cells with biotin induced changes in gene expression congruent with the in vivo repletion studies within 24 to 48 hours. 


\section{MATERIALS AND METHODS}

Animal model of biotin depletion and repletion

Adult male Sprague-Dawley rats ( $250 \mathrm{~g}$; ten animals total) were fed a biotin-deficiency diet consisting of normal rodent chow supplemented with $20 \%$ egg white (ICN Biochemicals) using a well-established model (Dakshinamurti and Cheah-Tan 1968; Dakshinamurti and Mistry 1963). Animals were fed this diet for six weeks, then half (5 rats) were switched to a normal diet and injected with $10 \mathrm{mg} / \mathrm{kg}$ biotin I.P. (Biotin Repletion, BR) or were maintained on the biotindeficiency diet and injected with saline vehicle (Biotin Depletion, BD). One week following injection, animals were humanely sacrificed using $\mathrm{CO}_{2}$ asphyxiation euthanasia. Pancreata were collected then rinsed in sterile cold saline and frozen in liquid nitrogen until use. All animal studies were approved by the University of Manitoba Animal Care Committee in accordance with the guidelines of the Canadian Council on Animal Care.

\section{Tissue isolation and RNA extraction}

Pancreata were mechanically homogenized under Trizol using a Polytron, then total RNA isolated according to manufacturer's directions (Invitrogen), with the modification that a ratio of 4:1 Trizol:tissue was used. For long term storage, total RNA was stored in formamide. RNA concentration and purity was determined by absorbance at 260 and $280 \mathrm{~nm}$.

\section{Microarray analysis}

Total pancreatic RNA samples from five animals in each group (BD or BR) were pooled to ensure equal contribution from each animal to the group RNA sample. Samples were prepared according to the Affymetrix GeneChip Expression 3'-Amplification Labeling kit directions, with 
a modification that $5 \mu \mathrm{g}$ total RNA was used as a starting point. Samples were hybridized to Affymetrix GeneChip Rat Genome 2.0 microarrays and analyzed using GCOS software, with post-analysis performed using BioConductor and AffylmGUI. For comparisons between samples, a cutoff of a 2-fold change in gene expression (with $\mathrm{P}<0.05$ ) was selected, and any genes called by GCOS as "absent" in both samples were ignored. We analyzed genes that exhibited expression changes of at least 2-fold, and that were statistically-significant and called as expressed in at least one sample, with the DAVID (Database for Annotation, Visualization and Integrated Discovery) Bioinformatics Resources 6.7. The results of this analysis identified enriched cell function pathways using ontological term identifiers (Huang da et al. 2009a, 2009b). For DAVID analysis, default settings for Functional Annotation Clustering were used with medium classification stringency.

\section{Cell culture and treatment}

Rat pancreatic acinar AR42J cells (CRL 1492) were purchased from ATCC. Cells were maintained in F-12K medium (ATCC) supplemented with 20\% FBS and 1\% penicillin/streptomycin, at $37^{\circ} \mathrm{C}$ under humidified conditions of $5 \% \mathrm{CO}_{2}$. Alternatively, cells were maintained in biotin-free DME medium (Sigma-Aldrich) supplemented with $0.5 \%$ FBS and $1 \%$ penicillin/streptomycin under identical conditions of humidity, temperature and $\mathrm{CO}_{2}$ concentration. Biotin (Sigma-Aldrich) was dissolved in sterile deionized water to yield a $5 \mathrm{mM}$ stock solution. Biotin dilution for cell treatments was made using no-serum starvation media (either F-12K or DME as required). AR42J cells were treated with 50 pM biotin or vehicle for 24 or 48 hours. 


\section{RNA isolation and $q P C R$ analysis}

Total RNA was isolated from AR42J cells post-treatment using a commercially available purification kit as per manufacturer's instructions (Thermo Scientific). RNA concentrations were determined and purity confirmed using 260/280 nm absorbance ratio. RNA samples were assayed using an iQ5 multicolor real-time PCR thermocycler (Bio-Rad) using the qScript OneStep SYBR Green qRT- PCR kit for iQ (Quanta Biosciences). Gene-specific primers were synthesized commercially (Integrated DNA Technologies); primer sequences and qPCR cycle settings are listed in Supplementary Table S1. mRNA abundance was calculated using the $2^{-\Delta \Delta \mathrm{Ct}}$ method and normalized to GAPDH.

\section{Statistical analysis}

For qPCR studies, results represent mean \pm standard error of the mean for at least 3 independent experiments. Data was analyzed by two-tailed Student's $t$ test, with $P<0.05$ considered statistically significant. 


\section{RESULTS}

As expected, six weeks of biotin depletion (BD) in rats resulted in spotty alopecia (not shown), indicative of the biotin deficient status of these animals. Pancreatic gene expression was analyzed by Affymetrix Rat Genome 2.0 microarrays, and a total of 972 transcripts exhibited differential expression of at least 2-fold between BR and BD groups (449 up-regulated in BR and 524 down-regulated in BR, representing $\sim 3 \%$ of the transcripts on the array), with $P<0.05$. The expression data was normalized using the Affymetrix GCOS software, and exhibited no indication of sample bias (Figure 1).

The Affymetrix identifiers of all 972 differentially-expressed genes were uploaded to the DAVID Bioinformatics resource for ontological analysis. These genes were mapped to 754 equivalent DAVID identifiers and used for further analysis. DAVID employs a modified Fisher Exact $P$-Value (the EASE score) to assess whether transcripts in the list of up/down-regulated transcripts belong to specific gene ontology categories that are represented in the list more frequently than would be expected by random chance. The resulting Enrichment Score provides a relative indication of how enriched these gene ontology categories are in the transcript list. Ontology terms sharing an enrichment score are also related by the member genes populating those terms. Using this approach, the most enriched annotation cluster corresponded to extracellular matrix ontology terms (Table 1), indicative of alterations in extracellular matrix gene expression. Other noteworthy enriched clusters mapped to signal/stimulus response (cluster 2), carbohydrate/pattern binding (cluster 3), endocrine pancreas function (cluster 4) and secretion (cluster 6). An additional cluster 12, with an Enrichment Score of 2.75, included the GO terms vitamin binding, vitamin B6 binding, pyridoxal phosphate binding and cofactor binding $(P<0.05$ for all terms; not shown), fitting with the variant biotin status of these animals. 
We further analyzed gene expression patterns using DAVID to identify Functional Annotation Clustering by KEGG (Kyoto Encyclopedia of Genes and Genomes) pathways. Using this approach, the most significantly altered pathway by EASE score was PPAR signaling (Table 2). Other notable pathways exhibiting alteration between BR and BD animals included ECM (extracellular matrix)-receptor interaction, maturity onset diabetes of the young, and insulin signaling. These findings were consistent with the GO term changes previously noted, including indicators of altered extracellular matrix expression and pancreatic function.

Examination of gene expression changes following biotin repletion revealed a variety of noteworthy features. Numerous markers of inflammation were significantly elevated in BD samples compared to BR (Table 3). Similarly, various collagens were expressed at significantly higher levels in the depleted BD samples, in agreement with the gene ontology analysis results indicative of enrichment of extracellular matrix genes and fibrosis, while angiotensinogen and BNIP3 were further suggestive of pancreatic injury (Table 4).

Biotin repletion appears to result in induction of pancreatic repair processes, as noted by Annotation Cluster 4 highlighting pancreatic development (Table 1). Congruent with this finding, we noted induction of several mediators of pancreas repair including PapI/Reg3b, PapII/Reg3a and osteopontin (Table 5). These regulators have been previously noted to be induced during acute pancreatitis (Dusetti et al. 2000).

Given the expression alterations highlighted by Annotation Cluster 6, suggestive of alterations in pancreatic secretory function, transcripts involved in endocrine and exocrine function were examined. Expression of transcripts encoding glucagon and $\alpha$-amylase $1 \mathrm{~A}$ were higher in BR samples, while insulin exhibited a modest although significant decrease (Table 6). 
Transcriptional regulators of pancreatic secretory functions, including HNF6, FoxA2, Mist1 and pancreas-specific transcription factor 1a were also higher following biotin repletion.

We confirmed a subset of microarray-identified gene expression changes using quantitative PCR analysis of biotin-depleted and biotin-repleted samples. The injury/fibrosis-related transcript Bnip3 was approximately $60 \%$ lower in biotin repleted samples compared to biotin depleted samples (Figure 2A). Col5a1 showed a similar trend although the results were not statistically significant $(P=0.0564)$. Similarly, the repair transcripts PapI and PapII were dramatically higher in repleted samples, approximately 200 -fold higher than in the biotin depleted samples (Figure 2B).

To begin to examine whether gene expression changes may be directly regulated by biotin, we treated AR42J pancreatic cells with 50 pM biotin for 24 or 48 hours. In preliminary dosedependency studies ranging from picomolar to micromolar concentrations of biotin (not shown), we observed maximal PapI and PapII gene expression response at this concentration. PapI and PapII were rapidly up-regulated in a time-dependent fashion by biotin treatment (Figure 3A). This induction was observed regardless of whether the cells were grown in the normal growth medium for the cells, F-12K which contains $\sim 300 \mathrm{nM}$ biotin, or in biotin-free DME medium, suggesting that exogenous biotin could alter gene expression independently of the presence of endogenous biotin. The repair transcript osteopontin/Spp1 exhibited a non-significant trend to a decrease at 24 hours in F-12K but an induction in DME, and was significantly induced at 48 hours in either medium. The injury/fibrosis-related transcripts Bnip3, Col1a1 and Col5a1 were significantly down-regulated by biotin treatment at both 24 and 48 hours (Figure 3B). The secretory function of these cells may also be altered by biotin treatment: similar to the results in the in vivo study, Glut4 expression was reduced by biotin at both time points and in both media 
(Figure 3C). Conversely, HNF6, which was induced in the biotin repleted pancreas, exhibited a biphasic response in $\mathrm{F}-12 \mathrm{~K}$ medium, with a significant reduction at 24 hours of biotin treatment but a 3-fold induction at 48 hours. In contrast, HNF6 expression was induced by biotin in DME medium at both 24 and 48 hours. 


\section{DISCUSSION}

The present data suggests that biotin repletion following depletion resembles the repair processes that occur during pancreatitis. A number of damage markers, including signs of inflammation and fibrosis, were elevated in BD pancreata compared to BR (Tables 1 to 4, Figure 2A), suggesting that damage had occurred in the depleted organs and was being ameliorated following repletion. These changes suggest that chronic biotin depletion may have more substantive negative effects on pancreatic function than previously assumed.

The induction of genes associated with tissue repair following biotin repletion (Table 5, Figure 2B) suggests that damage to the pancreas may be transient and/or reversible to some degree. Furthermore, the induction of these genes after biotin supplementation suggests that biotin may, itself, trigger repair processes. This finding is consistent with previous reports that biotin supplementation can improve pancreatic function in diabetes, at least in part by regulating glucokinase expression (McCarty 2007; Zhang et al. 1997). The altered expression of genes associated with pancreatic endocrine and exocrine function (Table 6) following biotin repletion further suggest that biotin may exert direct effects on pancreatic function.

Of particular note is the very high degree of induction of the pancreatitis-associated proteins PapI/Reg3b and PapII/Reg3b by biotin. The Pap family consists of three related C-type lectins, including PapIII, and all three members have been reported to be secreted after the induction of pancreatitis (Frigerio et al. 1993; Keim and Loffler 1986). Indeed, PapI has been reported to be induced in multiple tissues in response to insult, including both acute and chronic pancreatitis, hypoxia, toxin exposure and diabetes, as well as following organ transplant, in Crohn's diseases, ulcerative colitis and animal models of inflammatory bowel disease (Baeza et al. 2001; Chen et al. 1996; Dieckgraefe et al. 2000; Lawrance et al. 2001; Masciotra et al. 1995; McKie et al. 1996; 
Orelle et al. 1992; van der Pijl et al. 1997). Pap expression is induced in the brain tissue of Alzheimer patients and in injured sensory and motor neurons, and is also elevated in adenocarcinoma and hepatocarcinoma (Averill et al. 2002; Livesey et al. 1997; Ozturk et al. 1989; Simon et al. 2003; Xie et al. 2003). Pap induction thus appears to be a general response to tissue damage or disease.

It has been suggested that the induction of Pap gene expression may form part of the normal response to inflammatory stress (Closa et al. 2007). The pancreatic acinar cells are the primary source of Pap in pathological conditions, and serum factors from rats with acute pancreatitis, but not from healthy rats, could induce endogenous PapI gene expression in the acinar cell line AR42J (Bodeker et al. 1998; Dusetti et al. 1994). PapI may behave as an anti-inflammatory similar to IL-10, both of which inhibit activation of neutrophils and macrophages (Moore et al. 2001). Both also inhibit IL-6 and TNF $\alpha$ synthesis and block translocation of NFאB (Vasseur et al. 2004). The IL-10-related cytokine IL-22 has been shown to activate the expression of PapI in epithelial cells (Aggarwal et al. 2001). Dexamethasone exerts an anti-inflammatory effect in acute pancreatitis at least in part via up-regulation of Pap gene expression, possibly through a glucocorticoid response element in the Pap gene promoter (Dusetti et al. 1996; Kandil et al. 2006). That biotin status may influence inflammatory diseases is indicated by findings that biotin deficiency in mice up-regulates TNF $\alpha$ production and biotin repletion down-regulates TNF $\alpha$ production (Kuroishi et al. 2008).

Pap may also work by attenuating apoptosis, as Pap expression confers significant resistance to apoptosis induced by TNF $\alpha$ or oxidative stress (Christa et al. 1994; Malka et al. 2000; Ortiz et al. 1998). Conversely, administration of anti-Pap antibodies increased the severity of pancreatitis (Zhang et al. 2004). Similarly, expression of all three Pap isoforms has been knocked down via 
delivery of anti-sense oligodeoxyribonucleotides introduced by intrapancreatic injection. When delivered two days prior to induction of acute pancreatitis, the pathology was exacerbated: serum levels of amylase and c-reactive protein increased, as did pancreas wet weight indicative of edema (Vasseur et al. 2004; Zhang et al. 2004). Pancreata also exhibited increased signs of leukocyte infiltration, and peripheral blood mononuclear cells showed increased expression of IL-1 and IL-4. In contrast, induction of Pap expression prior to the triggering of necrotizing pancreatitis significantly improved animal survival (Fiedler et al. 1998).

The exact mechanism by which Pap expression is induced in response to disease is unclear. As noted above, dexamethasone may act directly at the gene promoter, but whether a similar mechanism holds true for other inducers of Pap remains to be seen. Our data suggests that PapI and PapII gene expression rises in response to biotin repletion, but the mechanism responsible remains to be determined. We cannot rule out that Pap expression rises indirectly, after biotin repletion has already induced other repair processes in the pancreas. However, given the critical role of Pap in normal pancreatic function, and the improvements seen in pancreatitis following Pap administration, it seems more likely that Pap induction by biotin may be a directly regulated process. Using the rat pancreatic acinar AR42J cell line, we found that PapI and PapII expression was rapidly and potently up-regulated in response to biotin treatment (Figure 3A), supporting the possibility that altered Pap gene expression upon biotin repletion in vivo represents a biotininduced event, and not merely a generalized response to stress. Intriguingly, we also found that biotin induced a reduction in the expression of Bnip3, associated with cell injury, and the fibrotic collagens Colla1 and Col5a1 (Figure 3B). Glut4 and HNF6 expression were also altered following biotin treatment similar to the changes observed following biotin repletion in vivo. Intriguingly, we observed a better fit of gene expression data in biotin-treated AR42J cells with 
the in vivo repletion data when the cells were maintained in biotin-free DME medium compared to biotin-containing F-12K medium. This is perhaps not surprising since the in vivo studies compared biotin repletion to depletion, thus the addition of biotin to DME may better model the in vivo situation. Together, these results suggest that biotin may exert direct positive and negative effects on a variety of gene targets, consistent with improved cell health and function although the precise mechanism remains unknown. 


\section{ACKNOWLEDGEMENTS}

This work was supported by a grant from the St. Boniface Hospital Foundation to KD. RAB was the recipient of a doctoral research studentship from the Canadian Institutes of Health Research and the Manitoba Health Research Council. The assistance of Sari Yakubovich, Viktoriya Mozolevska and Nina Aroutiounova is gratefully acknowledged. 


\section{REFERENCES}

Aggarwal, S., Xie, M. H., Maruoka, M., Foster, J., and Gurney, A. L. 2001. Acinar cells of the pancreas are a target of interleukin-22. J. Interferon Cytokine Res. 21(12): 1047-1053.

Albarracin, C., Fuqua, B., Geohas, J., Juturu, V., Finch, M. R., and Komorowski, J. R. 2007. Combination of chromium and biotin improves coronary risk factors in hypercholesterolemic type 2 diabetes mellitus: a placebo-controlled, double-blind randomized clinical trial. J Cardiometab. Syndr. 2(2): 91-97.

Albarracin, C. A., Fuqua, B. C., Evans, J. L., and Goldfine, I. D. 2008. Chromium picolinate and biotin combination improves glucose metabolism in treated, uncontrolled overweight to obese patients with type 2 diabetes. Diabetes Metab. Res. Rev. 24(1): 41-51.

Averill, S., Davis, D. R., Shortland, P. J., Priestley, J. V., and Hunt, S. P. 2002. Dynamic pattern of reg-2 expression in rat sensory neurons after peripheral nerve injury. J. Neurosci. 22(17): 7493-7501.

Baeza, N., Sanchez, D., Christa, L., Guy-Crotte, O., Vialettes, B., and Figarella, C. 2001. Pancreatitis-associated protein (HIP/PAP) gene expression is upregulated in NOD mice pancreas and localized in exocrine tissue during diabetes. Digestion 64(4): 233-239.

Bodeker, H., Fiedler, F., Keim, V., Dagorn, J. C., and Iovanna, J. L. 1998. Pancreatitisassociated protein is upregulated in mouse pancreas during acute pancreatitis. Digestion 59(3): 186-191.

Chauhan, J., and Dakshinamurti, K. 1991. Transcriptional regulation of the glucokinase gene by biotin in starved rats. J. Biol. Chem. 266(16): 10035-10038. 
Chen, P., Arias, A. E., Morisset, J., Calvo, E., Dagorn, J. C., Iovanna, J., et al. 1996. Presence of pancreatitis-associated protein in pancreatic acinar cells of rats treated with chlorophenylalanine methyl ester. Pancreas 13(2): 147-153.

Christa, L., Felin, M., Morali, O., Simon, M. T., Lasserre, C., Brechot, C., et al. 1994. The human HIP gene, overexpressed in primary liver cancer encodes for a C-type carbohydrate binding protein with lactose binding activity. FEBS Lett. 337(1): 114-118.

Closa, D., Motoo, Y., and Iovanna, J. L. 2007. Pancreatitis-associated protein: from a lectin to an anti-inflammatory cytokine. World J. Gastroenterol. 13(2): 170-174.

Dakshinamurti, K. 2005. Biotin--a regulator of gene expression. J. Nutr. Biochem. 16(7): 419423.

Dakshinamurti, K. 2006. Vitamin Receptors. In Reviews in Cell Biology and Molecular Medicine. Wiley-VCH Verlag GmbH \& Co. KGaA.

Dakshinamurti, K., and Cheah-Tan, C. 1968. Biotin-mediated synthesis of hepatic glucokinase in the rat. Arch. Biochem. Biophys. 127(1): 17-21.

Dakshinamurti, K., and Li, W. 1994. Transcriptional regulation of liver phosphoenolpyruvate carboxykinase by biotin in diabetic rats. Mol. Cell. Biochem. 132(2): 127-132.

Dakshinamurti, K., and Mistry, S. P. 1963. Tissue and intracellular distribution of biotin-C1400H in rats and chicks. J. Biol. Chem. 238: 294-296.

Dieckgraefe, B. K., Stenson, W. F., Korzenik, J. R., Swanson, P. E., and Harrington, C. A. 2000. Analysis of mucosal gene expression in inflammatory bowel disease by parallel oligonucleotide arrays. Physiol. Genomics 4(1): 1-11. 
Dusetti, N. J., Mallo, G., Dagorn, J. C., and Iovanna, J. L. 1994. Serum from rats with acute pancreatitis induces expression of the PAP mRNA in the pancreatic acinar cell line AR-42J. Biochem Biophys. Res. Commun. 204(1): 238-243.

Dusetti, N. J., Mallo, G. V., Ortiz, E. M., Keim, V., Dagorn, J. C., and Iovanna, J. L. 1996. Induction of lithostathine/reg mRNA expression by serum from rats with acute pancreatitis and cytokines in pancreatic acinar AR-42J cells. Arch. Biochem. Biophys. 330(1): 129-132.

Dusetti, N. J., Tomasini, R., Azizi, A., Barthet, M., Vaccaro, M. I., Fiedler, F., et al. 2000. Expression profiling in pancreas during the acute phase of pancreatitis using cDNA microarrays. Biochem. Biophys. Res. Commun. 277(3): 660-667.

Fiedler, F., Croissant, N., Rehbein, C., Iovanna, J. L., Dagorn, J. C., van Ackern, K., et al. 1998. Acute-phase response of the rat pancreas protects against further aggression with severe necrotizing pancreatitis. Crit. Care Med. 26(5): 887-894.

Frigerio, J. M., Dusetti, N. J., Keim, V., Dagorn, J. C., and Iovanna, J. L. 1993. Identification of a second rat pancreatitis-associated protein. Messenger RNA cloning, gene structure, and expression during acute pancreatitis. Biochemistry 32(35): 9236-9241.

Geohas, J., Daly, A., Juturu, V., Finch, M., and Komorowski, J. R. 2007. Chromium picolinate and biotin combination reduces atherogenic index of plasma in patients with type 2 diabetes mellitus: a placebo-controlled, double-blinded, randomized clinical trial. Am. J. Med. Sci. 333(3): 145-153.

Huang da, W., Sherman, B. T., and Lempicki, R. A. 2009a. Bioinformatics enrichment tools: paths toward the comprehensive functional analysis of large gene lists. Nucleic Acids Res. 37(1): $1-13$. 
Huang da, W., Sherman, B. T., and Lempicki, R. A. 2009b. Systematic and integrative analysis of large gene lists using DAVID bioinformatics resources. Nat. Protoc. 4(1): 44-57.

Kandil, E., Lin, Y. Y., Bluth, M. H., Zhang, H., Levi, G., and Zenilman, M. E. 2006.

Dexamethasone mediates protection against acute pancreatitis via upregulation of pancreatitisassociated proteins. World J. Gastroenterol. 12(42): 6806-6811.

Keim, V., and Loffler, H. G. 1986. Pancreatitis-associated protein in bile acid-induced pancreatitis of the rat. Clin. Physiol. Biochem. 4(2): 136-142.

Kuroishi, T., Endo, Y., Muramoto, K., and Sugawara, S. 2008. Biotin deficiency up-regulates TNF-alpha production in murine macrophages. J. Leukoc. Biol. 83(4): 912-920.

Lawrance, I. C., Fiocchi, C., and Chakravarti, S. 2001. Ulcerative colitis and Crohn's disease: distinctive gene expression profiles and novel susceptibility candidate genes. Hum. Mol. Genet. 10(5): 445-456.

Lazo de la Vega-Monroy, M. L., Larrieta, E., German, M. S., Baez-Saldana, A., and FernandezMejia, C. 2013. Effects of biotin supplementation in the diet on insulin secretion, islet gene expression, glucose homeostasis and beta-cell proportion. J. Nutr. Biochem. 24(1): 169-177. Livesey, F. J., O'Brien, J. A., Li, M., Smith, A. G., Murphy, L. J., and Hunt, S. P. 1997. A Schwann cell mitogen accompanying regeneration of motor neurons. Nature 390(6660): 614618.

Maebashi, M., Makino, Y., Furukawa, Y., Ohinata, K., Kimura, S., and Sato, T. 1993.

Therapeutic evaluation of the effect of biotin on hyperglycemia in patients with non-insulin dependent diabetes mellitus. J. Clin. Biochem. Nutr. 14: 211-218. 
Malka, D., Vasseur, S., Bodeker, H., Ortiz, E. M., Dusetti, N. J., Verrando, P., et al. 2000. Tumor necrosis factor alpha triggers antiapoptotic mechanisms in rat pancreatic cells through pancreatitis-associated protein I activation. Gastroenterology 119(3): 816-828.

Masciotra, L., Lechene de la Porte, P., Frigerio, J. M., Dusetti, N. J., Dagorn, J. C., and Iovanna, J. L. 1995. Immunocytochemical localization of pancreatitis-associated protein in human small intestine. Dig. Dis. Sci. 40(3): 519-524.

McCarty, M. F. 2007. Exenatide and biotin in conjunction with a protein-sparing fast for normalization of beta cell function in type 2 diabetics. Med. Hypotheses 69(4): 928-932. McKie, A. T., Simpson, R. J., Ghosh, S., Peters, T. J., and Farzaneh, F. 1996. Regulation of pancreatitis-associated protein (HIP/PAP) mRNA levels in mouse pancreas and small intestine. Clin. Sci. (Lond.) 91(2): 213-218.

Moore, K. W., de Waal Malefyt, R., Coffman, R. L., and O'Garra, A. 2001. Interleukin-10 and the interleukin-10 receptor. Annu. Rev. Immunol. 19: 683-765.

Orelle, B., Keim, V., Masciotra, L., Dagorn, J. C., and Iovanna, J. L. 1992. Human pancreatitisassociated protein. Messenger RNA cloning and expression in pancreatic diseases. J. Clin. Invest. 90(6): 2284-2291.

Ortega-Cuellar, D., Hernandez-Mendoza, A., Moreno-Arriola, E., Carvajal-Aguilera, K., PerezVazquez, V., Gonzalez-Alvarez, R., et al. 2010. Biotin starvation with adequate glucose provision causes paradoxical changes in fuel metabolism gene expression similar in rat (Rattus norvegicus), nematode (Caenorhabditis elegans) and yeast (Saccharomyces cerevisiae). J.

Nutrigenet. Nutrigenomics 3(1): 18-30. 
Ortiz, E. M., Dusetti, N. J., Vasseur, S., Malka, D., Bodeker, H., Dagorn, J. C., et al. 1998. The pancreatitis-associated protein is induced by free radicals in AR4-2J cells and confers cell resistance to apoptosis. Gastroenterology 114(4): 808-816.

Ozturk, M., de la Monte, S. M., Gross, J., and Wands, J. R. 1989. Elevated levels of an exocrine pancreatic secretory protein in Alzheimer disease brain. Proc. Natl. Acad. Sci. U. S. A. 86(2): 419-423.

Revilla-Monsalve, C., Zendejas-Ruiz, I., Islas-Andrade, S., Baez-Saldana, A., PalominoGaribay, M. A., Hernandez-Quiroz, P. M., et al. 2006. Biotin supplementation reduces plasma triacylglycerol and VLDL in type 2 diabetic patients and in nondiabetic subjects with hypertriglyceridemia. Biomed. Pharmacother. 60(4): 182-185.

Romero-Navarro, G., Cabrera-Valladares, G., German, M. S., Matschinsky, F. M., Velazquez, A., Wang, J., et al. 1999. Biotin regulation of pancreatic glucokinase and insulin in primary cultured rat islets and in biotin-deficient rats. Endocrinology 140(10): 4595-4600.

Simon, M. T., Pauloin, A., Normand, G., Lieu, H. T., Mouly, H., Pivert, G., et al. 2003. HIP/PAP stimulates liver regeneration after partial hepatectomy and combines mitogenic and antiapoptotic functions through the PKA signaling pathway. FASEB J. 17(11): 1441-1450. Singer, G. M., and Geohas, J. 2006. The effect of chromium picolinate and biotin supplementation on glycemic control in poorly controlled patients with type 2 diabetes mellitus: a placebo-controlled, double-blinded, randomized trial. Diabetes Technol. Ther. 8(6): 636-643. van der Pijl, J. W., Boonstra, J. G., Barthellemy, S., Smets, Y. F., Hermans, J., Bruijn, J. A., et al. 1997. Pancreatitis-associated protein: a putative marker for pancreas graft rejection. Transplantation 63(7): 995-1003. 
Vasseur, S., Folch-Puy, E., Hlouschek, V., Garcia, S., Fiedler, F., Lerch, M. M., et al. 2004. p8 improves pancreatic response to acute pancreatitis by enhancing the expression of the antiinflammatory protein pancreatitis-associated protein I. J. Biol. Chem. 279(8): 7199-7207.

Xie, M. J., Motoo, Y., Iovanna, J. L., Su, S. B., Ohtsubo, K., Matsubara, F., et al. 2003. Overexpression of pancreatitis-associated protein (PAP) in human pancreatic ductal adenocarcinoma. Dig. Dis. Sci. 48(3): 459-464.

Zhang, H., Kandil, E., Lin, Y. Y., Levi, G., and Zenilman, M. E. 2004. Targeted inhibition of gene expression of pancreatitis-associated proteins exacerbates the severity of acute pancreatitis in rats. Scand. J. Gastroenterol. 39(9): 870-881.

Zhang, H., Osada, K., Sone, H., and Furukawa, Y. 1997. Biotin administration improves the impaired glucose tolerance of streptozotocin-induced diabetic Wistar rats. J. Nutr. Sci. Vitaminol. (Tokyo) 43(3): 271-280. 


\section{Table 1. Functional annotation clustering by Gene Ontology terms.}

The top seven functional annotation clusters are given following DAVID analysis of 754

transcripts differentially expressed between BR and BD at least 2-fold. GO ID, gene ontology

identification number; count indicates the number of transcripts (out of 754) mapping to a given

GO ID with corresponding percentage listed; EASE, Modified Fisher Exact P Value.

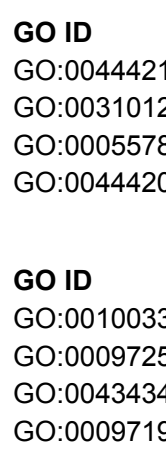

GO ID

GO:0030246

GO:0001871

GO:0030247

GO:0005539

GO:0008201

GO ID

GO:0031016

GO:0031018

GO:0035270

GO ID

GO:0042803

GO:0042802

GO:0046983

GO ID

GO:0030141

GO:0031982

GO:0016023

GO:0031410

GO:0031988

GO:0044433

GO ID

GO:0001944

GO:0001568

GO:0048514
Annotation Cluster 1; Enrichment Score: 8.18

\section{Term}

extracellular region part

extracellular matrix

proteinaceous extracellular matrix

extracellular matrix part

Annotation Cluster 2; Enrichment Score: 4.57

\section{Term}

response to organic substance

response to hormone stimulus

response to peptide hormone stimulus

response to endogenous stimulus

\begin{tabular}{|c|c|c|}
\hline Count & $\%$ & EASE \\
\hline 72 & 9.5 & $5.60 \mathrm{E}-11$ \\
\hline 38 & 5.0 & $2.23 \mathrm{E}-10$ \\
\hline 34 & 4.5 & $1.24 \mathrm{E}-09$ \\
\hline 15 & 2.0 & 1.19E-04 \\
\hline Count & $\%$ & EASE \\
\hline 68 & 9.0 & $5.00 \mathrm{E}-06$ \\
\hline 43 & 5.7 & 1.69E-05 \\
\hline 24 & 3.2 & $5.00 \mathrm{E}-05$ \\
\hline 44 & 5.8 & 1.19E-04 \\
\hline Count & $\%$ & EASE \\
\hline 31 & 4.1 & 6.55E-05 \\
\hline 15 & 2.0 & 3.02E-04 \\
\hline 15 & 2.0 & 3.02E-04 \\
\hline 13 & 1.7 & 1.01E-03 \\
\hline 10 & 1.3 & 2.77E-03 \\
\hline Count & $\%$ & EASE \\
\hline 10 & 1.3 & $2.95 \mathrm{E}-05$ \\
\hline 6 & 0.8 & $3.61 \mathrm{E}-04$ \\
\hline 8 & 1.1 & 3.57E-02 \\
\hline
\end{tabular}

Annotation Cluster 5; Enrichment Score: 3.03

\section{Term}

protein homodimerization activity

identical protein binding

protein dimerization activity

Annotation Cluster 6; Enrichment Score: 2.95

Term

secretory granule

vesicle

cytoplasmic membrane-bounded vesicle

cytoplasmic vesicle

membrane-bounded vesicle

cytoplasmic vesicle part

Annotation Cluster 7; Enrichment Score: 2.88

Term

vasculature development

blood vessel development

blood vessel morphogenesis

$\begin{array}{rrrl}\text { Count } & \% & & \text { EASE } \\ 28 & & 3.7 & 3.24 \mathrm{E}-04 \\ 43 & & 5.7 & 3.77 \mathrm{E}-04 \\ 35 & & 4.6 & 6.68 \mathrm{E}-03\end{array}$

$\begin{array}{cccl}\text { Count } & \% & & \text { EASE } \\ 22 & & 2.9 & 4.59 \mathrm{E}-04 \\ 48 & & 6.4 & 5.57 \mathrm{E}-04 \\ 41 & & 5.4 & 7.81 \mathrm{E}-04 \\ 45 & & 6.0 & 9.54 \mathrm{E}-04 \\ 42 & & 5.6 & 9.68 \mathrm{E}-04 \\ 16 & & 2.1 & 1.14 \mathrm{E}-02\end{array}$

$\begin{array}{cccl}\text { Count } & \% & & \text { EASE } \\ 23 & & 3.1 & 3.55 \mathrm{E}-04 \\ 22 & & 2.9 & 5.98 \mathrm{E}-04 \\ 16 & & 2.1 & 1.07 \mathrm{E}-02\end{array}$




\section{Table 2. Functional annotation clustering by KEGG terms.}

Differentially-expressed transcripts ( $>2$-fold) were analyzed by DAVID as in Table 1, with functional clustering according to KEGG terms.

$\begin{array}{ll}\text { KEGG ID } & \text { Term } \\ \text { rno03320 } & \text { PPAR signaling pathway } \\ \text { rno04512 } & \text { ECM-receptor interaction } \\ \text { rno04510 } & \text { Focal adhesion } \\ \text { rno00564 } & \text { Glycerophospholipid metabolism } \\ \text { rno00260 } & \text { Glycine, serine and threonine metabolism } \\ \text { rno04950 } & \text { Maturity onset diabetes of the young } \\ \text { rno00565 } & \text { Ether lipid metabolism } \\ \text { rno04640 } & \text { Hematopoietic cell lineage } \\ \text { rno04270 } & \text { Vascular smooth muscle contraction } \\ \text { rno04920 } & \text { Adipocytokine signaling pathway } \\ \text { rno00620 } & \text { Pyruvate metabolism } \\ \text { rno04610 } & \text { Complement and coagulation cascades } \\ \text { rno04144 } & \text { Endocytosis } \\ \text { rno04910 } & \text { Insulin signaling pathway }\end{array}$

$\begin{array}{rll}\text { Count } & \% & \text { EASE } \\ 13 & 1.7 & 2.30 \mathrm{E}-05 \\ 13 & 1.7 & 8.85 \mathrm{E}-05 \\ 20 & 2.7 & 3.15 \mathrm{E}-04 \\ 10 & 1.3 & 7.93 \mathrm{E}-04 \\ 7 & 0.9 & 0.001565 \\ 6 & 0.8 & 0.003453 \\ 6 & 0.8 & 0.011225 \\ 9 & 1.2 & 0.013236 \\ 11 & 1.5 & 0.015961 \\ 8 & 1.1 & 0.018192 \\ 6 & 0.8 & 0.019725 \\ 8 & 1.1 & 0.022652 \\ 15 & 2.0 & 0.033278 \\ 11 & 1.5 & 0.041346\end{array}$

Table 3. Expression of inflammation-related transcripts.

Relative transcript expression is given as fold change in BR samples compared to BD, thus a negative number is indicative of higher expression in BD. All listed transcript expression changes are $\mathrm{P}<0.05$. AffyID, Affymetrix identifier.

$\begin{array}{llll}\text { AffyID } & \text { Gene name } & \text { Gene symbol } & \text { BR/BD (fold) } \\ \text { 1387796_at } & \text { Arachidonate 12-lipoxygenase } & \text { Alox12 } & -2.1 \\ \text { 1370405_at } & \text { Mast cell protease 1 precursor } & \text { RMCP1 } & -2.3 \\ \text { 1387173_at } & \text { Mast cell chymase 1 } & \text { Cma1 } & -2.3 \\ \text { 1387902_a_at } & \text { Similar to NGF-binding Ig light chain } & \text { LOC500183 } & -2.8 \\ \text { 1388275_at } & \text { T cell receptor beta chain } & \text { LOC100912777 } & -2.0 \\ \text { 1371016_at } & \text { T cell receptor active alpha-chain C-region } & \text { LOC290071 } & -2.3 \\ \text { 1370218_at } & \text { Lactate dehydrogenase B } & \text { Ldhb } & -2.6 \\ \text { 1388166_at } & \text { Immunoglobulin heavy chain 6 } & \text { Igh6 } & -2.6\end{array}$




\section{Table 4. Expression of injury/fibrosis-related transcripts.}

Expression fold-change is listed as in Table 3.

$\begin{array}{lllc}\text { AffyID } & \text { Gene name } & \text { Gene symbol } & \text { BR/BD (fold) } \\ \text { 1387811_at } & \text { Angiotensinogen } & \text { Agt } & -2.8 \\ \text { 1387805_at } & \text { Bcl2 adenovirus E1B 19 kDa-interacting protein 3 } & \text { Bnip3 } & -2.3 \\ \text { 1370864_at } & \text { Collagen I } \alpha 1 & \text { Col1a1 } & -2.0 \\ \text { 1369955_at } & \text { Collagen V } \alpha 1 & \text { Col5a1 } & -2.1 \\ \text { 1368347_at } & \text { Collagen V } \alpha 3 & \text { Col5a3 } & -2.5 \\ \text { 1390846_at } & \text { Collagen XVla1 } & \text { Col16a1 } & -2.1\end{array}$

Table 5. Expression of pancreatic repair transcripts.

Expression fold-change is listed as in Table 3. Expression in acute pancreatitis is derived from a previously published cDNA profile (Dusetti et al. 2000).

$\begin{array}{lllcc}\text { AffyID } & \begin{array}{l}\text { Gene name } \\ \text { Pancreatitis-associated protein 1 (Papl) / Regenerating }\end{array} & \text { Gene symbol } & \text { BR/BD (fold) } & \begin{array}{c}\text { Acute } \\ \text { pancreatitis }\end{array} \\ \text { 1368238_at } & \begin{array}{l}\text { islet-derived 3 beta } \\ \text { Pancreatitis-associated protein 2 (PaplI) / Regenerating }\end{array} & \text { Reg3b } & +34.3 & +13.3 \\ \text { 1387930_at } & \text { islet-derived 3 alpha } & \text { Reg3a } & +14.9 & +8.5 \\ \text { 1367581_a_at } & \text { Osteopontin / Secreted phosphoprotein 1 } & \text { Spp1 } & +2.5 & +3.6\end{array}$


Table 6. Expression of endocrine and exocrine transcripts.

Expression fold-change is listed as in Table 3.

$\begin{array}{llll}\text { AffylD } & \text { Gene name } & \text { Gene symbol } & \text { BR/BD (fold) } \\ \text { 1371034_at } & \text { Hepatocyte Nuclear Factor 6 / One cut homeobox 1 } & \text { HNF6 } & +3.5 \\ \text { 1387760_a_at } & \text { Hepatocyte Nuclear Factor 6 / One cut homeobox 1 } & \text { HNF6 } & +3.0 \\ \text { 1368711_at } & \text { Hepatocyte Nuclear Factor 3 / Forkhead box A2 } & \text { FoxA2 } & +3.5 \\ \text { 136988__at } & \text { Glucagon } & \text { Gcg } & +3.0 \\ \text { 1387815_at } & \text { Insulin } & \text { Ins1 } & -1.3 \\ \text { 1370359_at } & \text { a-amylase 1A } & \text { Amy1a } & +3.0 \\ \text { 1387228_at } & \text { Glucose transporter 2 / Slc2a2 } & \text { Glut2 } & +2.1 \\ \text { 1367989_at } & \text { Glucose transporter 4 / Slc2a4 } & \text { Glut4 } & -3.5 \\ \text { 1387212_at } & \text { Mist1 transcription factor } & \text { Bhlha15 } & +2.1 \\ \text { 1387660_at } & \text { Islet amyloid polypeptide } & \text { lapp } & +3.0 \\ \text { 1369787_at } & \text { Cholecystokinin A receptor } & \text { Cckar } & +2.1 \\ \text { 1387700_at } & \text { Cholecystokinin A receptor } & \text { Cckar } & +2.0 \\ \text { 1369803_at } & \text { Pancreas-specific transcription factor 1a } & \text { Ptf1a } & +2.0 \\ \text { 1369410_at } & \text { Cis-Golgi p28 } & \text { p28 } & -2.5\end{array}$




\section{FIGURE LEGENDS}

Figure 1. Quality analysis of microarray data. Microarray data was analyzed using GCOS, BioConductor and AffylmGUI software. (A) Scatter plot of all transcript intensities for BD (x axis) and BR (y axis) samples, demonstrating a linear relationship without evidence of bias. (B) MA plot of microarray data following data normalization, with BR/BD signal intensity ratio (M) plotted against the average signal intensity (A). The distribution around $M=0$ reveals a lack of difference in expression of most transcripts between the two samples, as expected, and indicates successful normalization of the data.

Figure 2. qPCR analysis of gene expression following biotin repletion. Total RNA was isolated from BD or BR rat pancreata used for the microarray study and mRNA expression of injury/fibrosis transcripts Bnip3 and Col5a1 (A) or repair transcripts PapI and PapII (B) were analyzed by qPCR. Results were normalized to GAPDH and to the corresponding BD sample. Results represent mean $\pm \mathrm{SEM}$ for $\mathrm{n}=4-5 ; * \mathrm{P}<0.05$ vs. $\mathrm{BD}$ sample.

Figure 3. Biotin-mediated regulation of gene expression in AR42J cells. AR42J pancreatic acinar cells were grown in either biotin-containing F-12K medium or biotin-free DME medium and treated with vehicle or $50 \mathrm{pM}$ biotin for 24 or 48 hours. Total RNA was isolated and assayed by qPCR for expression of repair transcripts PapI, PapII and Spp1 (A), for injury/fibrosis transcripts Bnip3, Col1a1 and Col5a1 (B), or for secretory function transcripts Glut4 and HNF6 (C). Results were normalized to GAPDH and to the corresponding vehicle control. Results represent mean $\pm \mathrm{SEM}$ for $\mathrm{n}=3-5 ; * \mathrm{P}<0.05$ vs. vehicle control. 
a

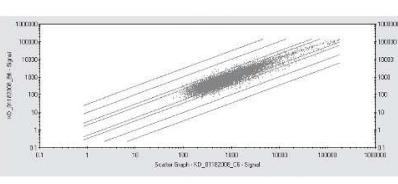

b

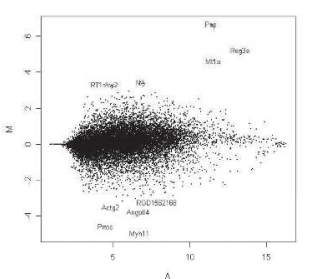

Figure 1

$254 \times 874 \mathrm{~mm}(300 \times 300$ DPI $)$

https://mc06.manuscriptcentral.com/cjpp-pubs 


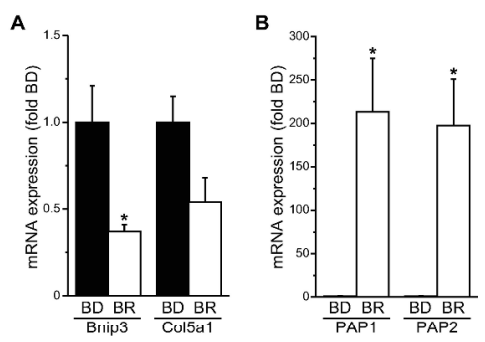

Figure 2

$268 \times 893 \mathrm{~mm}(300 \times 300 \mathrm{DPI})$ 

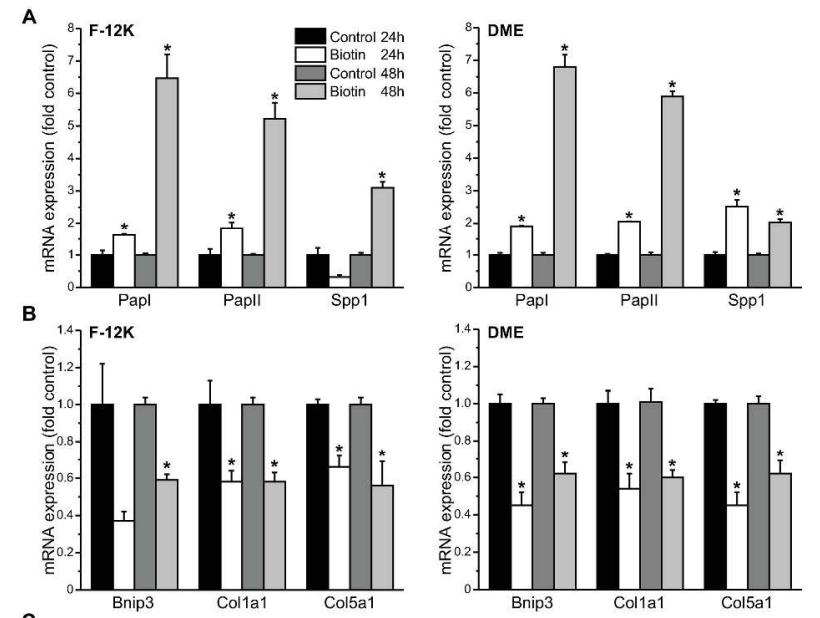

C
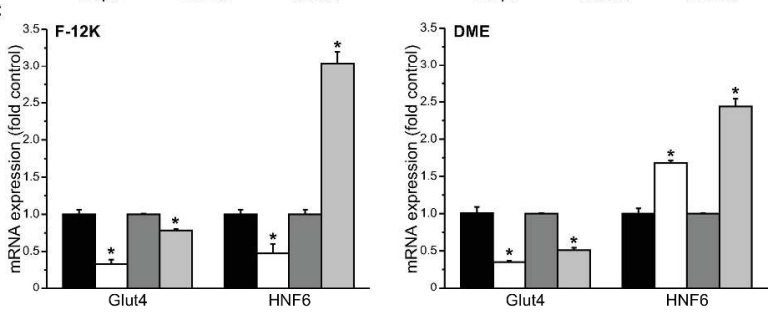

Figure 3

$268 \times 536 \mathrm{~mm}(300 \times 300$ DPI $)$

https://mc06.manuscriptcentral.com/cjpp-pubs 